Jaqueline Alves Paz

\title{
A Fratura no Tempo: O Pensamento sem Amparos, o Juízo e os Fragmentos do Passado em Hannah Arendt
}

\section{Dissertação de Mestrado}

Dissertação apresentada como requisito para a obtenção do grau de Mestre ao programa de Pós-Graduação em História Social da Cultura do Departamento de História da PUC-Rio

Orientador: Marcelo Gantus Jasmin 
Jaqueline Alves Paz

A Fratura no Tempo: O Pensamento sem Amparos, o Juízo e os Fragmentos do Passado em Hannah Arendt

\author{
Dissertação de Mestrado
}

Dissertação apresentada como requisito para a obtenção do grau de Mestre ao programa de Pós-Graduação em História Social da Cultura do Departamento de História da PUC-Rio. Aprovada pela comissão organizadora abaixo assinada.

\author{
Prof. Marcelo Gantus Jasmin \\ Orientador \\ Departamento de História -PUC-Rio \\ Prof. Eduardo Jardim \\ Departamento de Filosofia - PUC-Rio \\ Prof. Heloísa Starling \\ UFMG
}

Rio de Janeiro, 16 de agosto de 2002. 
Todos os direitos reservados. É proibida a reprodução total ou parcial do trabalho sem a autorização da universidade, da autora e do orientador.

Jaqueline Alves Paz

Graduou-se em História na Universidade do Estado do Rio de Janeiro (UERJ) em 1999.

Ficha Catalográfica

Paz, Jaqueline Alves

A fratura no tempo: o pensamento sem amparo, o juízo e os fragmentos do passado em Hannah Arendt / Jaqueline Alves Paz; orientador: Marcelo Gantus Jasmin. - Rio de Janeiro: PUC, Departamento de História, 2002.

v., 83 f.: $29,7 \mathrm{~cm}$

1. Dissertação (mestrado) Pontifícia Universidade Católica do Rio de Janeiro, Departamento de História.

Inclui referências bibliográficas.

1. História - Teses. 2. 
Dedico essa dissertação àquele que ainda vai chegar, trazendo consigo a semente da boa nova: Guilherme 


\section{Agradecimentos:}

Ao meu orientador Marcelo Gantus Jasmin que aceitou me orientar, apesar de meus devaneios filosóficos e as minhas dificuldades na escrita.

Agradeço ao Departamento de História da PUC-Rio, seus professores e funcionários, pela gentileza constante.

Ao CNPQ, pela bolsa oferecida, recurso sem o qual teria sido impossível me enveredar pelos caminhos da dissertação.

Aos professores que participaram da comissão examinadora.

Agradeço a todos aqueles que tornaram possível este trabalho, agradeço também a todos aqueles que porventura venha a esquecer de agradecer.

À Aparecida pela revisão precisa e competente.

Aos meus pais, Justino e Marli, por terem suportado a minha convivência, a minha falta de humor, as minhas angústias e depressões.

Ao meu companheiro, Paulo Henrique, por seu apoio e compreensão, que foram fundamentais para o término desse trabalho.

Às minhas amigas Roberta Cardoso e Renata Moura que me ajudaram a enfrentar todas as dificuldades, estando sempre presentes.

À Clícia Maria pela leitura e correções precisas.

A todos os amigos e parentes que me ajudaram sem perceber nessa minha árdua tarefa de escrita 


\section{Resumo}

Paz, Jaqueline Alves; Jasmin, Marcelo Gantus. A fratura no tempo: o pensamento sem amparos, o juízo e os fragmentos do passado em Hannah Arendt. Rio de Janeiro, 2002. 83p. Dissertação de Mestrado Departamento de História, Pontifícia Universidade Católica do Rio de Janeiro.

Esse trabalho refere-se ao pensamento de Arendt e suas considerações acerca do pensar e do julgar, tendo como eixo norteador: a compreensão do conceito de história. A relação entre o julgar como uma atividade do espírito voltada para o passado, a preocupação com a memória, impedindo que os acontecimentos se percam no fluir do próprio tempo, e a necessidade portanto desse pensar como momento cristalizador das idéias, permitindo que o mundo sobreviva com seu passado e garanta a sobrevivência da novidade daqueles que ainda chegarão. Partindo das considerações arendtianas sobre a temporalidade, presenciamos com a modernidade um novo momento, a partir da ruptura com a tradição e um espécie de lacuna aberta no tempo, tornando necessário portanto, segundo Arendt que re-pensemos conceitos como história, política e filosofia.

\section{Palavras-chave}

Hannah Arendt; história; filosofia; tempo; tradição 


\section{Abstract}

Paz, Jaqueline Alves; Jasmin, Marcelo Gantus (Advisor). The rupture in time: the supportless thought, the judgement and the fragments of the past in Hannah Arendt. Rio de Janeiro, 2002. 83p. MSc. Dissertation Departamento de História, Pontifícia Universidade Católica do Rio de Janeiro.

This paper refers to Arendt's thoughts and considerations on thinking and judging, its guiding line being the understanding of the concept of history. The relation between judging as a spiritual activity facing the past, the concern about memory - preventing events to get lost into the time flow - and the consecutive necessity of thinking as a crystallizing moment of the ideas allowing the world to survive its past and avowing the survival of novelty in those still to come. From Arendt's considerations on temporality, we witness a new moment within modernity, departing from the rupture with tradition and a hiatus open in time, making it necessary to rethink concepts such as history, politcs and philosophy.

\section{Keywords}

Hannah Arendt; history; philosophy; time; tradition 


\section{Sumário}

1. Introdução 10

2. Reflexões acerca do pensamento Arendtiano 14

$\begin{array}{lll}2.1 & \text { Eichmann e a banalidade do mal } & 14\end{array}$

2.2 A amizade como amor mundi 23

$\begin{array}{lll}2.3 & \text { Filosofia e política } & 28\end{array}$

2.4 Compreensão e conhecimento 33

2.5 O Juízo reflexionante de Kant 39

2.6 O Dois-em-um do pensamento 47

2.7 Considerações sobre a História 51

3. Conclusão 64

4. Referências Bibliográficas $\quad 68$ 
... o tempo, o tempo, esse algoz às vezes suave, às vezes mais terrivel, demônio absoluto conferindo qualidade a todas as coisas, é ele ainda hoje e sempre quem decide e por isso a quem me curvo cheio de medo e erguido em suspense me perguntando qual o momento, o momento preciso da transposição? Que instante terrivel é esse que marca o salto? Que massa de vento, que fundo de espaço concorrem para levar ao limite? O limite em que as coisas já desprovidas de vibração deixam de ser simplesmente vida na corrente do dia-a-dia para ser vida nos subterrâneos da memória ...

Raduan Nassar, Lavoura Arcaica 